\title{
Selective formic acid dehydrogenation at low temperature over a RuO2/COF pre- catalyst synthesized on the gram scale
}

Gonçalves, Liliana P. L.; Christensen, David Benjamin; Meledina, Maria; Salonen, Laura M.; Petrovykh, Dmitri Y.; Carbó-Argibay, Enrique; Sousa, Juliana P. S.; Soares, O. Salomé G. P.; Pereira, M. Fernando R.; Kegnæs, Søren

Total number of authors:

11

Published in:

Catalysis Science and Technology

Link to article, DOI:

10.1039/d0cy00145g

Publication date:

2020

Document Version

Peer reviewed version

Link back to DTU Orbit

Citation (APA):

Gonçalves, L. P. L., Christensen, D. B., Meledina, M., Salonen, L. M., Petrovykh, D. Y., Carbó-Argibay, E., Sousa, J. P. S., Soares, O. S. G. P., Pereira, M. F. R., Kegnæs, S., \& Kolen'ko, Y. V. (2020). Selective formic acid dehydrogenation at low temperature over a $\mathrm{RuO} / \mathrm{COF}$ pre-catalyst synthesized on the gram scale. Catalysis Science and Technology, 10, 1991-1995. https://doi.org/10.1039/d0cy00145g

\section{General rights}

Copyright and moral rights for the publications made accessible in the public portal are retained by the authors and/or other copyright owners and it is a condition of accessing publications that users recognise and abide by the legal requirements associated with these rights.

- Users may download and print one copy of any publication from the public portal for the purpose of private study or research.

- You may not further distribute the material or use it for any profit-making activity or commercial gain

- You may freely distribute the URL identifying the publication in the public portal 


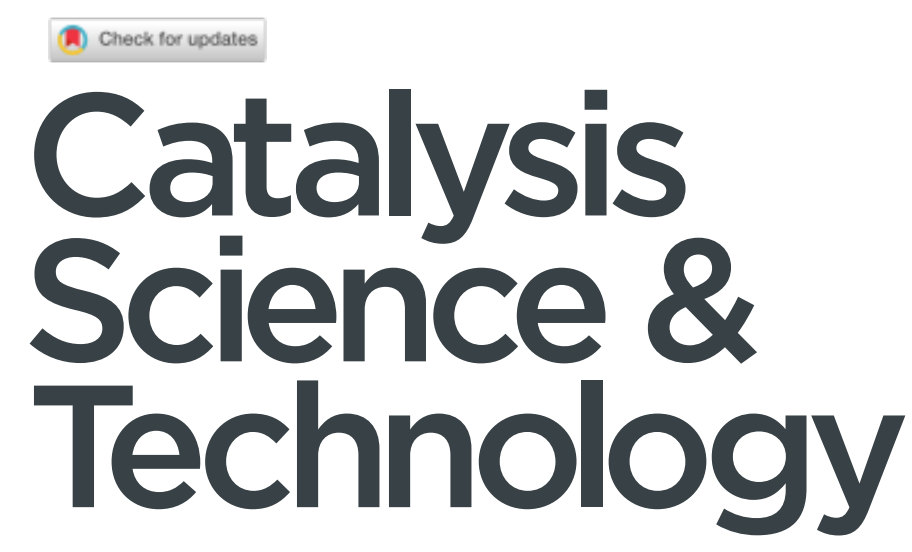

\section{Accepted Manuscript}

This article can be cited before page numbers have been issued, to do this please use: L. P. L. Gonçalves,

D. B. Christensen, M. Meledina, L. M. Salonen, D. Y. Petrovykh, E. Carbó-Argibay, J. P. S. Sousa, S. Soares,

M. F. Pereira, S. Kegnæs and Y. V. Kolen'ko, Catal. Sci. Technol., 2020, DOI: 10.1039/D0CY00145G.
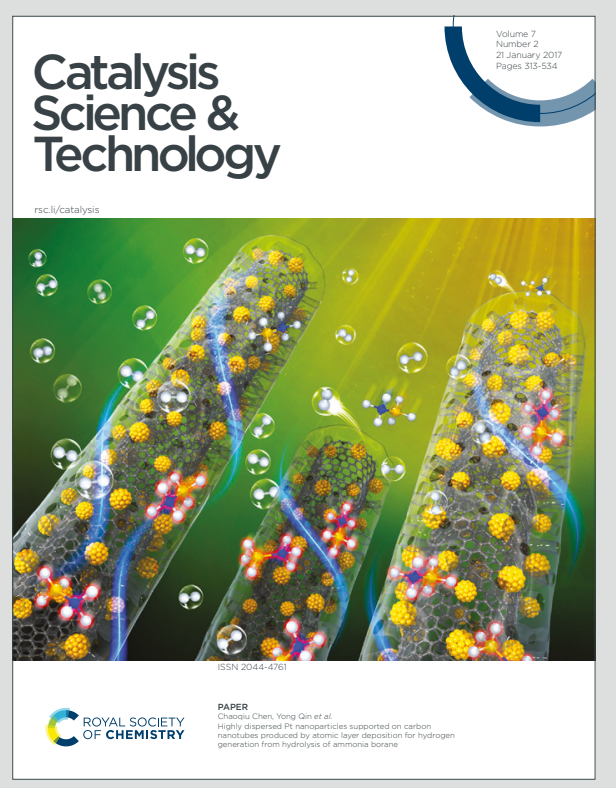

This is an Accepted Manuscript, which has been through the Royal Society of Chemistry peer review process and has been accepted for publication.

Accepted Manuscripts are published online shortly after acceptance, before technical editing, formatting and proof reading. Using this free service, authors can make their results available to the community, in citable form, before we publish the edited article. We will replace this Accepted Manuscript with the edited and formatted Advance Article as soon as it is available.

You can find more information about Accepted Manuscripts in the Information for Authors.

Please note that technical editing may introduce minor changes to the text and/or graphics, which may alter content. The journal's standard Terms \& Conditions and the Ethical guidelines still apply. In no event shall the Royal Society of Chemistry be held responsible for any errors or omissions in this Accepted Manuscript or any consequences arising from the use of any information it contains. 
Received 00th January 20xx, Accepted 00th January 20xx DOI: $10.1039 / \times 0 \times x 00000 x$

\section{Selective formic acid dehydrogenation at low temperature over $\mathrm{RuO}_{2} / \mathrm{COF}$ pre-catalyst synthesized on the gram scale}

\author{
Liliana P. L. Gonçalves, ${ }^{\text {a, b }}$ David B. Christensen, ${ }^{c}$ Maria Meledina, ${ }^{d, e}$ Laura M. Salonen, ${ }^{a}$ Dmitri Y.
} Petrovykh, ${ }^{a}$ Enrique Carbó-Argibay, ${ }^{a}$ Juliana P. S. Sousa, ${ }^{a}$ O. Salomé G. P. Soares, ${ }^{b}$ M. Fernando R. Pereira, ${ }^{\mathrm{b}}$ Søren Kegnæs, ${ }^{\mathrm{c},{ }^{*}}$ Yury V. Kolen'ko, ${ }^{\mathrm{a},{ }^{*}}$

\begin{abstract}
A pre-catalyst, consisting of $\mathrm{RuO}_{2}$ nanoparticles and clusters anchored on TpBD-Me $\mathrm{Me}_{2} \mathrm{COF}$, was synthesized. During catalytic formic acid dehydrogenation, $\mathrm{RuO}_{2}$ undergoes in situ reduction to metallic Ru, forming an active and selective catalyst, which outperforms the commercial Ru-C catalyst. The chemical structure of COF supporting material is maintained during stability testing.
\end{abstract}

Formic acid (FA) is an important chemical that is used, for example, in silage and animal feed, leather and tanning industries, as well as in pharmaceutical and food industries. More interestingly, FA can be used as fuel for direct FA fuel cells (DFAFC), which generate electrical energy. Alternatively, FA can be used as $\mathrm{H}_{2}$ carrier via dehydrogenation to $\mathrm{CO}_{2}$ and $\mathrm{H}_{2}$, with the resultant $\mathrm{H}_{2}$ used as fuel for hydrogen fuel cells.1,2

Compared to other $\mathrm{H}_{2}$ carriers, FA possesses high gravimetric and volumetric capacity $\left(4.4 \mathrm{wt} \%\right.$ and $\left.53.4 \mathrm{~g} \mathrm{~L}^{-1}\right)$, and is liquid under ambient conditions, which makes it a promising practical $\mathrm{H}_{2}$ carrier. Furthermore, FA can be produced directly from biomass or $\mathrm{CO}_{2}$, which allows a carbon-neutral cycle for the production and storage of renewable hydrogen..$^{1,2}$ In addition, FA could be used as a sustainable carbon monoxide source. ${ }^{3}$

Depending on the catalyst and the reaction conditions, the decomposition of $\mathrm{FA}$ can produce $\mathrm{H}_{2}$ and $\mathrm{CO}_{2}$ through dehydrogenation or the alternative production of $\mathrm{CO}$ can occur. $^{2}$ Therefore, the selectivity of the catalyst is crucial in

a International Iberian Nanotechnology Laboratory (INL), Avenida Mestre José Veiga, 4715-330 Braga, Portugal

*e-mail: yury.kolenko@inl.int (Yu. V. Kolen'ko)

${ }^{b}$ Laboratory of Separation and Reaction Engineering - Laboratory of Catalysis and Materials (LSRE-LCM), Faculdade de Engenharia, Universidade do Porto, Rua Dr. Roberto Frias, 4200-465 Porto, Portugal

c Technical University of Denmark, DTU Chemistry, Kemitorvet 207, 2800 Kgs. Lyngby, Denmark

*e-mail: skk@kemi.dtu.dk (S. Kegnæs)

d RWTH Aachen University, Central Facility for Electron Microscopy, D-52074 Aachen, Germany

e Forschungszentrum Jülich GmbH, Ernst Ruska-Centre (ER-C 2), D-52425 Jülich, Germany

Electronic Supplementary Information (ESI) available: Materials and methods and additional characterization data, catalytic experiments (PDF).See DOI: $10.1039 / x 0 x x 00000 x$ order to obtain the delivered product. Homogeneous and heterogeneous catalysts have been proposed both in liquid ${ }^{4-6}$ and gas ${ }^{7-15}$ phase for FA dehydrogenation. Most of the catalysts, however, exhibit selectivities $<100 \%$ in the gas phase. The most used catalysts for FA decomposition reaction are Pd, $4,9-11 \mathrm{Au}^{-}{ }^{7-9}$ and $\mathrm{Pt}$-based ${ }^{12,13}$ due to the high conversion and selectivity that they achieve. High activity and selectivity has been obtained also with $\mathrm{Ru}$, which has been primarily investigated in the liquid phase as a homogeneous catalyst, ${ }^{5,6}$ and less extensively as a heterogeneous ${ }^{13,15}$ or immobilizedcomplex $^{14}$ catalyst. In contrast, for gas-phase FA dehydrogenation, studies of Ru-based catalysts are scarce when compared to Pd-, Pt-, Au-, and Ni-based catalysts. ${ }^{13,15}$ Hence, we were interested in investigating $\mathrm{RuO}_{2}$ nanoparticles (NPs) supported on $\mathrm{TpBD}-\mathrm{Me}_{2}$ (Figures $\mathrm{S} 1 \mathrm{a}, \mathrm{b}$ ) covalent organic framework (COF) as a pre-catalyst for this reaction. We envisioned that such pre-catalyst would eventually provide an active and selective catalytic system due to in situ reduction of $\mathrm{RuO}_{2}$ to $\mathrm{Ru}$ under reaction conditions.

COFs are crystalline porous materials with tunable pore structure. Owing to the high surface area, regular porosity, and structural uniformity, this class of materials is an interesting candidate to be used as catalyst support. ${ }^{16-18}$ Specifically, COFs themselves have been used as organocatalysts ${ }^{19}$ and as support for metals, ${ }^{16-18}$ providing high dispersion of the active catalyst. ${ }^{20}$ Unfortunately, the amount of COF that is synthesized per batch in a typical solvothermal synthesis is only in the order of tens to few hundreds of milligrams, which hinders their use in systematic studies and real applications. Furthermore, there is scarcity of using COFs for heterogeneous gas phase catalysis. ${ }^{17}$ In the current study, we employed TpBD-Me $\mathrm{M}_{2} \mathrm{COF}$, hereafter referred to as COF, synthesized using a procedure ${ }^{21}$ developed in our group that beneficially yields ca. $2 \mathrm{~g}$ of crystalline COF material in one batch. This specific COF was selected because of its high stability under harsh conditions ${ }^{22}$ and high $\mathrm{N}$-content that can be beneficial for the FA dehydrogenation reaction. ${ }^{12,15}$ In the COF synthesis protocol, 1,3,5-triformylphloroglucinol $(\mathrm{Tp})^{23}$ self-assembles with $\mathrm{o}$-tolidine $\left(\mathrm{BD}-\mathrm{Me}_{2}\right)$ to yield 
$\mathrm{TpBD}-\mathrm{Me}_{2}{ }^{21}$ as an orange solid (Figure S1). We further anchored the $\mathrm{RuO}_{2} \mathrm{NPs}$ on the as-synthesized coF using a method reported elsewhere. ${ }^{24}$ Briefly, $\mathrm{RuCl}_{x} \cdot \mathrm{XH}_{2} \mathrm{O}$ is used as precursor and the NPs are precipitated using $\mathrm{NaOH}$.

We began by investigating the crystallinity of the obtained materials. The distances derived from the small-angle $\mathrm{X}$-ray scattering (SAXS) pattern of COF (Figure 1a) correspond well to those reported in the literature for TpBD-Me ${ }_{2}{ }^{25}$ Importantly, the crystallinity of the COF was maintained after anchoring the $\mathrm{RuO}_{2}$ NPs (Figure 1a). Inductively coupled plasma-optical emission spectroscopy (ICP-OES) shows that the Ru loading is $2.4 \%$. The specific surface area $\left(S_{\mathrm{BET}}\right)$ of COF was estimated to be $520 \mathrm{~m}^{2} \mathrm{~g}^{-1}$ (Figure S2a, Table S1), consistent with the literature. ${ }^{21,25}$ After precipitating $\mathrm{RuO}_{2}$ onto TpBD-Me $\mathrm{M}_{2}, \mathrm{~S}_{\mathrm{BET}}$ increases to $630 \mathrm{~m}^{2} \mathrm{~g}^{-1}$ due to anchoring of high surface area $\mathrm{RuO}_{2} \mathrm{NPs}$, which results in augmentation of the overall texture of Ru-COF. We further characterized the surface chemistry of the as-synthesized materials using $X$-ray photoelectron spectroscopy (XPS) (Figure 1b, S3 and Table S2). In the Ru-COF, the main $\mathrm{Ru} 3 \mathrm{p}_{3 / 2}$ component is at the binding energy (BE) of $462.8 \mathrm{eV}$ (Figure 1b), which matches the value reported for hydrated $\mathrm{RuO}_{2}$ catalyst prepared via an analogous procedure (further information in the ESI). ${ }^{26-29}$

We used annular dark-field scanning transmission electron microscopy (ADF-STEM) imaging coupled with energydispersive $\mathrm{X}$-ray spectroscopy (STEM-EDX) mapping to investigate the morphology and the chemical composition of the synthesized COF and Ru-COF. ${ }^{30-32}$ Figure 2a shows ADFSTEM overview of agglomerated $\approx 10-50 \mathrm{~nm}$ COF particles. An ordered honeycomb structure is clearly visualized in Figure $2 b$, confirming the crystalline state of COF with a pore size of $\approx 6.1 \AA$. ADF-STEM image of Ru-COF pre-catalyst is shown in Figure 2c. The bright contrast features correspond to Ru-rich NPs of $\approx 1.2 \mathrm{~nm}$ in diameter (Figure $2 \mathrm{~d}$ ) anchored on the COF, along with single Ru atoms and clusters of few-atoms spread within the COF support (Figure 2c). Together with this, some of Ru-rich NPs form agglomerates of $\approx 10 \mathrm{~nm}$ in size (Figure S4). Considering the estimated particle size, the dispersion of the NPs is $\approx 100 \%$ (ESI), suggesting that all the Ru should be available
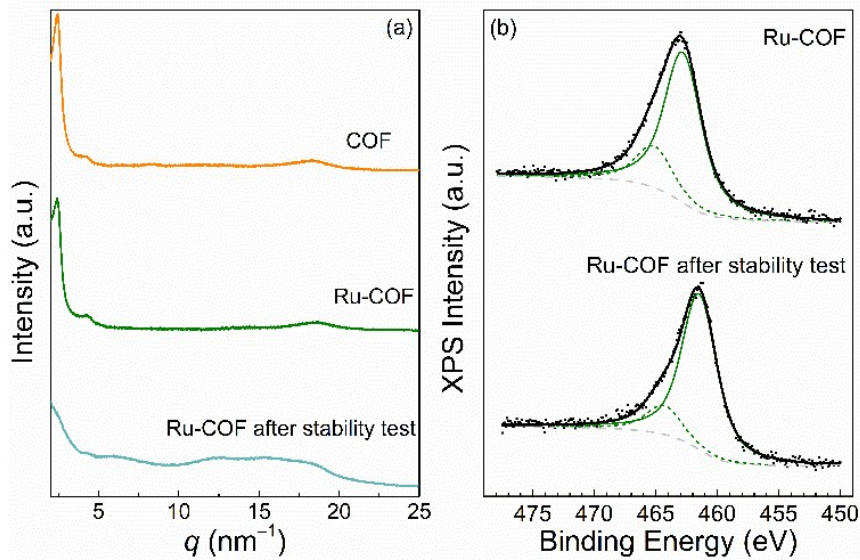

Figure 1. (a) SAXS patterns of COF, Ru-COF, and Ru-COF after stability test. (b) Highresolution XPS data for $\mathrm{Ru}_{3} \mathrm{p}_{3 / 2}$ region of Ru-COF and Ru-COF after stability test (symbols: raw data; black lines: overall fits; coloured lines: fits of individual components; grey dashed lines: background).

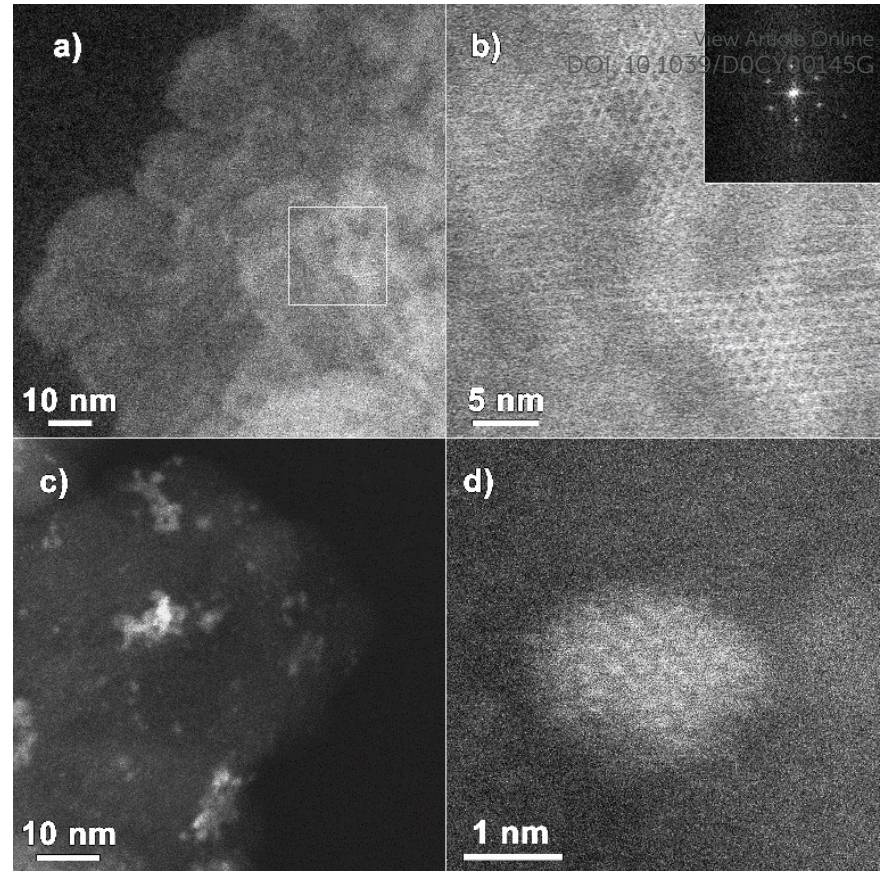

Figure 2. (a) ADF-STEM image of COF, together with magnified area (b) indicated by a white square in (a) and a corresponding fast Fourier transform (FFT) in the inset; (c) ADFSTEM image of Ru-COF pre-catalyst, along with high resolution image of a $\mathrm{RuO}_{2} \mathrm{NP}$.

for the catalytic reaction.

Figure S5 shows an ADF-STEM image of Ru-COF pre-catalyst together with corresponding STEM-EDX maps evidencing the bright contrast particles to be Ru-rich.

Having confirmed the presence of $\approx 1.2 \mathrm{~nm} \mathrm{RuO} 2 \mathrm{NPs}$ anchored on the crystalline COF, we tested the Ru-COF pre-catalyst in a light-off gas-phase FA dehydrogenation experiment and compared it with a Ru-C commercial catalyst with a particle size $<2 \mathrm{~nm}(\mathrm{ESI})$. The yield to $\mathrm{H}_{2}\left(Y_{\mathrm{H} 2}\right)$ is presented in Figure 3a while the conversion of FA $(X)$ and selectivity to $\mathrm{H}_{2} \quad\left(S_{H_{2}}\right)$ are summarized in Figures S7a,b. In the first cycle, the catalyst exhibits high activity towards FA dehydrogenation from $120^{\circ} \mathrm{C}$ onwards, reaching $50 \%$ conversion at $155^{\circ} \mathrm{C}$ (Figure S7a) and a maximum $Y_{\mathrm{H} 2}$ of $97 \%$ at $200{ }^{\circ} \mathrm{C}$ (Figure 3a). Importantly, the catalyst outperforms the commercial Ru-C control catalyst, showing higher $X$ at a lower temperature and higher maximum $Y_{H 2}$. The $S_{H 2}$ remained nearly constant $(\approx 98 \%)$ during the first cycle across the full range of the tested temperatures (Figure $\mathrm{S7b}$ ). In a negative control, no activity for FA dehydrogenation was observed when COF was used as catalyst (data not shown), confirming that the active phase is Ru-based. In the second catalytic run, a loss of $\approx 40 \%$ in activity was observed for both our Ru-COF catalyst and Ru-C, however, for our catalyst the $S_{H 2}$ increased to $\approx 100 \%$ (Figure $3 a$, S7).

Next, we performed a long time-on-stream stability test. Since reasonable deactivation was observed at temperatures above $120^{\circ} \mathrm{C}$ (Figure S7c), the stability tests were carried out at this temperature (Figure $3 \mathrm{~b}$ ). During the first hour after reaching $120^{\circ} \mathrm{C}$, the catalyst achieves $\approx 24 \% Y_{\mathrm{H} 2}$. Afterwards, the $Y_{\mathrm{H} 2}$ shows a slight decrease over the following $23 \mathrm{~h}$, becoming stable at $\approx 11 \%$, with the amount of CO generated (data not shown) being much lower than that at higher temperatures and 
close to the detection limit, marking the selectivity of our catalyst. The reference Ru-C catalyst exhibited a similar behaviour, however, the $Y_{\mathrm{H} 2}$ was generally about half of that of our catalyst. Notably, as the reactions are conducted at low temperatures, the $S_{H_{2}}$ is most likely determined by the watergas shift equilibrium, leading to the low amount of $\mathrm{CO}$ observed, and consequently, to high selectivity towards hydrogen.

To gain insight into the possible active catalytic phase, we analysed our catalyst after stability testing by SAXS, ADF-STEM, and XPS. The SAXS pattern shows that COF crystallinity is lost after long time FA dehydrogenation (Figure 1a). At the same time, XPS analysis of the sample after the catalytic testing (Figure 1b, S3) indicates that the chemical structure of the COF support remains largely unchanged (ESI). ${ }^{33}$ These results suggest that the loss of crystallinity is due to delamination of $2 \mathrm{D}$ COF into 1D COF sheets, rather than a modification of its chemical structure (ESI). XPS also confirms that the $\mathrm{RuO}_{2} \mathrm{NPs}$ are reduced to metallic $\mathrm{Ru}$ under reaction conditions (ESI), however, some of the $\mathrm{RuO}_{2}$, likely in the core of the particles, is not fully reduced. Notably, ADF-STEM suggests sintering of the Ru NPs and clusters during catalytic testing, leading to $\approx 2.4 \mathrm{~nm}$ average size (Figure S6).

The complementary characterization techniques provide consistent insights into the catalytic process: we believe that the ultrasmall $\mathrm{RuO}_{2} \mathrm{NPs}$ are rapidly reduced to metallic $\mathrm{Ru}$ under the reaction conditions, ${ }^{27,34}$ and the metallic $\mathrm{Ru}$ further acts as active site for the dehydrogenation of FA, as we were envisioning originally. The consequent decrease in activity during the catalytic reaction (Figure $3 \mathrm{~b}$ ) is most likely related to sintering of the active Ru NPs (Figure S6). The loss of crystallinity and the associated delamination of the COF $(E S I)^{35}$ under the same conditions suggest this as one of the mechanisms that can promote the mobility and sintering of Ru. We observe a similar deactivation in the commercial Ru-C catalyst also likely associated with the increased size of Ru NPs.

The selectivity values determined for our catalyst at conversions of $5 \%, 20 \%, 50 \%$, and $95 \%\left(125,140,155\right.$, and $200{ }^{\circ} \mathrm{C}$, respectively) are presented in Figure $3 \mathrm{c}$ as a function of conversion and compared to state-of-the-art catalysts used for gas phase FA dehydrogenation. In all range of conversions, our catalyst exhibits selectivity values similar to those reported for high performance $\mathrm{Ru}-, \mathrm{Au}-, \mathrm{Pd}-$, and Pt-based catalysts, ${ }^{8-14}$ and

(a)
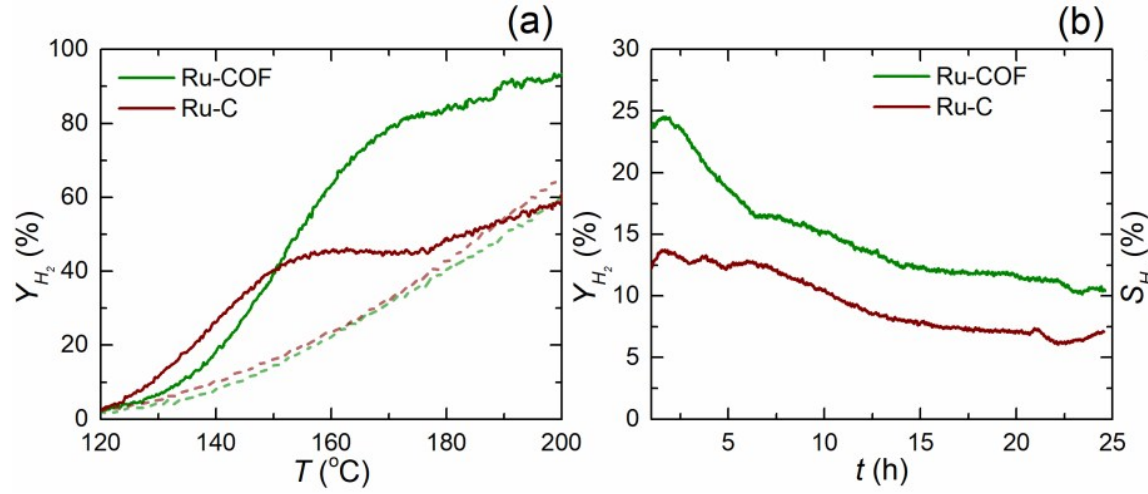

(b)

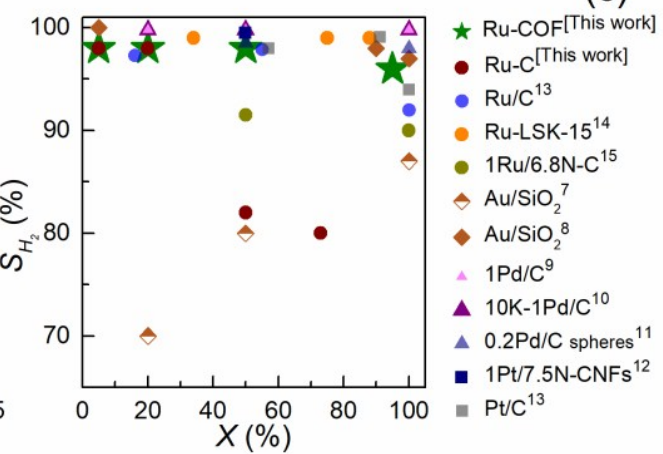

Figure 3. Comparison of catalytic performance of synthesized Ru-COF and commercial Ru-C control catalyst in the dehydrogenation of FA. Light-off curves for (a) $\mathrm{H}_{2}$ yield ( $\mathrm{H}_{\mathrm{H} 2}$ ) as a function of reaction temperature; (b) stability test performed at $120^{\circ} \mathrm{C}$ for $25 \mathrm{~h}$, monitoring $\mathrm{Y}_{\mathrm{H} 2}$ as a function of time; and (c) comparison of the $\mathrm{H}_{2}$ selectivity $\left(\mathrm{S}_{\mathrm{H} 2}\right)$ as a function of conversion $(X)$, for our catalyst (Ru-COF) the commercial catalyst tested (Ru-C) and state-of-the-art catalysts for gas-phase FA dehydrogenation.

higher selectivity than that reported for Ru-C and $\mathrm{d}_{\mathrm{A}} \mathrm{Au}_{\mathrm{u}}-\mathrm{SiO} \mathrm{O}_{2}$ catalysts. ${ }^{7,15}$ Significantly, our Ru-COF catallyst. 1 exhiblifs $Y$ highther $Y_{\mathrm{H} 2}=50 \%$ at $150{ }^{\circ} \mathrm{C}$, and $S_{\mathrm{H} 2} \approx 98 \%$ at $X=50 \%$, than those reported by Solymosi et al. for $\mathrm{Ru}-\mathrm{C}$ catalyst $\left(Y_{\mathrm{H} 2}=15 \%\right.$ at $150{ }^{\circ} \mathrm{C}$, and $S_{\mathrm{H} 2}=95 \%$ at $\left.X=66 \%\right),{ }^{13}$ by Zacharska and coworkers for Ru supported on $\mathrm{N}$-doped $\mathrm{C}$ nanofibers ( $Y_{\mathrm{H} 2} \approx 15 \%$ at $150{ }^{\circ} \mathrm{C}$, and $S_{H 2}=91.5 \%$ at $\left.X=50 \%\right),{ }^{15}$ as well as higher yield and similar selectivity as by Jia et al. for Pt supported on $\mathrm{N}$ doped $C$ nanofibers $\left(Y_{\mathrm{H} 2} \approx 30 \%\right.$ at $150{ }^{\circ} \mathrm{C}$, and $S_{\mathrm{H} 2}=99.5 \%$ at $X=50 \%) .{ }^{12}$ Notably, the aforementioned reports employ lower FA feed concentration and in the case of the aforementioned work of Solymosi et al., higher catalyst amount. ${ }^{12,13,15}$

The high $\mathrm{N}$ content of our COF support ( 9.9 wt\%, ESI) likely contributes to the high activity of the catalyst via two mechanisms. First, $\mathrm{N}$-doping of $\mathrm{C}$ nanofiber support has been reported to increase the activity of the Ru catalyst. ${ }^{15}$ In a second effect, reported for Pt catalyst on a similar $\mathrm{N}$-doped $\mathrm{C}$ nanofiber support, the improved activity of the catalyst in FA dehydrogenation reaction was associated with the presence of sub-nm Pt clusters, the formation of which was promoted by the $\mathrm{N}$-doping. ${ }^{12}$ While the analogous formation of sub-nm Ru clusters has not been observed for Ru supported on $\mathrm{N}$-doped $\mathrm{C}$ nanofibers, ${ }^{15}$ the combination of our method for the formation of $\mathrm{Ru}$ catalyst and of the $\mathrm{N}$-containing COF support does produce sub-nm Ru clusters with high dispersion over COF (Figure 2c, S5). Accordingly, we believe that both of the previously reported beneficial effects of $\mathrm{N}$ in the $\mathrm{C}$ support ${ }^{12,15}$ contribute to the high selectivity observed for our catalyst. The exact influence of the $\mathrm{N}$-content in the COF support on the catalyst performance is the subject of the ongoing research efforts.

In summary, TpBD-Me $\mathrm{M}_{2}$ COF was successfully synthesized, and used as support for $\mathrm{RuO}_{2}$ NPs. The COF presents a high surface area, well-defined porosity with a honeycomb structure as shown by ADF-STEM, and a high $\mathrm{N}$-content of $9.9 \mathrm{wt} \%$ from constituent organic building blocks. These features allowed the precipitation of well-dispersed $\mathrm{RuO}_{2} \mathrm{NPs}$ as well as small $\mathrm{RuO}_{2}$ clusters and single Ru atoms on the COF support, which were found to provide a good Ru-COF pre-catalyst for the in situ formation of an active and selective Ru catalyst for the FA dehydrogenation reaction.

The ruthenium phase in Ru-COF pre-catalyst was confirmed to 
be hydrated $\mathrm{RuO}_{2}$ by XPS analysis, which was further reduced to metallic Ru during initial stage of catalytic testing, thus forming the active sites for the dehydrogenation of FA. COF support maintained its chemical structure after $25 \mathrm{~h}$ of catalytic testing at $120^{\circ} \mathrm{C}$, as confirmed by XPS, although a loss of crystallinity of the support and some degree of sintering of the Ru NPs were observed.

The results obtained in this investigation provide an ambitious benchmark for further studies for the development of COFsupported catalysts for FA dehydrogenation reaction, as well as for other gas-phase dehydrogenation reactions at low temperatures. A particularly promising direction for future work indicated by our results is the selective synthesis of single Ru atom catalysts supported on COF for (de)hydrogenation.

\section{Conflicts of interest}

There are no conflicts to declare.

\section{Acknowledgment}

L.P.L.G. is thankful for the support to FCT PhD grant SFRH/BD/128986/2017. This work was financially supported by: Associate Laboratory LSRE-LCM - UID/EQU/50020/2019 funded by national funds through FCT/MCTES (PIDDAC). D.B.C. and S.K. are grateful for funding from the Independent Research Fund Denmark (grant no. 6111-00237), from Villum fonden (Grant No. 13158), and from Haldor Topsøe A/S.

\section{Notes and references}

1 A. K. Singh, S. Singh and A. Kumar, Catal. Sci. Technol., 2016, 6, 12-40.

2 X. Wang, Q. Meng, L. Gao, Z. Jin and J. Ge, Int. J. Hydrogen Energy, 2018, 43, 7055-7071.

3 W. Supronowicz, I. A. Ignatyev, G. Lolli, A. Wolf, L. Zhao and L. Mleczko, Green Chem., 2015, 17, 2904-2911.

4 Y. Kim and D. H. Kim, Appl. Catal. B Environ., 2019, 244, 684693.

5 Y. Pan, C. L. Pan, Y. Zhang, H. Li, S. Min, X. Guo, B. Zheng, H. Chen, A. Anders, Z. Lai, J. Zheng and K. W. Huang, Chem. Asian J., 2016, 11, 1357-1360.

6 C. Guan, D. D. Zhang, Y. Pan, M. Iguchi, M. J. Ajitha, J. Hu, H. Li, C. Yao, M. H. Huang, S. Min, J. Zheng, Y. Himeda, H. Kawanami and K. W. Huang, Inorg. Chem., 2017, 56, 438-445.

7 J. Mielby, A. J. Kunov-Kruse and S. Kegnæs, J. Catal., 2017, 345, 149-156.

8 A. Gazsi, T. Bánsági and F. Solymosi, J. Phys. Chem. C, 2011, 115, 15459-15466.

9 D. A. Bulushev, S. Beloshapkin and J. R. H. Ross, Catal. Today, 2010, 154, 7-12.

10 L. Jia, D. A. Bulushev and J. R. H. Ross, Catal. Today, 2016, 259, 453-459.

11 D. A. Bulushev, L. G. Bulusheva, S. Beloshapkin, T. O'Connor, A. V. Okotrub and K. M. Ryan, ACS Appl. Mater. Interfaces, 2015, 7, 8719-8726.

12 L. Jia, D. A. Bulushev, O. Y. Podyacheva, A. I. Boronin, L. S Kibis, E. Y. Gerasimov, S. Beloshapkin, I. A. Seryak, Z. R. Ismagilov and J. R. H. Ross, J. Catal., 2013, 307, 94-102.

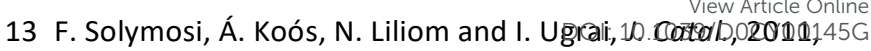
279, 213-219.

14 A. Beloqui Redondo, F. L. Morel, M. Ranocchiari and J. A. Van Bokhoven, ACS Catal., 2015, 5, 7099-7103.

15 M. Zacharska, O. Y. Podyacheva, L. S. Kibis, A. I. Boronin, B. V. Senkovskiy, E. Y. Gerasimov, O. P. Taran, A. B. Ayusheev, V. N. Parmon, J. J. Leahy and D. A. Bulushev, ChemCatChem, 2015, 7 2910-2917.

16 S.-Y. Ding, J. Gao, Q. Wang, Y. Zhang, W.-G. Song, C.-Y. Su, W. Wang, S.-Y. Ding Gao, J., Zhang, Y., Song, W.-G., Sy, C.-Y., Wang, W., S.-Y. Ding, J. Gao, Q. Wang, Y. Zhang, W.-G. Song, C.-Y. Su and W. Wang, J. Am. Chem. Soc., 2011, 133, 19816-19822. 17 D. Mullangi, S. Nandi, S. Shalini and S. Sreedhala, Sci. Rep., 2015, 5, 10876

18 G. J. Chen, X. B. Li, C. C. Zhao, H. C. Ma, J. L. Kan, Y. Bin Xin, C. $X$. Chen and Y. Bin Dong, Inorg. Chem., 2018, 57, 2678-2685. 19 S. Y. Zhang and X. Liu, J. Mater. Chem. A, 2018, 6, 374-382. 20 S. Kandambeth, K. Dey and R. Banerjee, J. Am. Chem. Soc. 2019, 141, 1807-1822.

21 A. Mellah, S. P. S. Fernandes, R. Rodríguez, J. Otero, J. Paz, J. Cruces, D. D. Medina, H. Djamila, B. Espiña and L. M. Salonen, Chem. Eur. J., 2018, 24, 10601-10605.

22 S. Kandambeth, A. Mallick, B. Lukose, M. V. Mane, T. Heine and R. Banerjee, J. Am. Chem. Soc., 2012, 134, 19524-19527. 23 J. H. Chong, M. Sauer, B. O. Patrick and M. J. MacLachlan, Org. Lett., 2003, 5, 3823-3826.

24 N. Mizuno and K. Yamaguchi, Catal. Today, 2008, 132, 18-26. 25 S. Chandra, S. Kandambeth, B. P. Biswal, B. Lukose, S. M. Kunjir, M. Chaudhary, R. Babarao, T. Heine and R. Banerjee, J. Am. Chem. Soc., 2013, 135, 17853-17861.

26 K. Yamaguchi, T. Koike, J. W. Kim and Y. Ogasawara, Chem. Eur. J., 2008, 14, 11480-11487.

27 D. J. Morgan, Surf. Interface Anal., 2015, 47, 1072-1079. 28 H. G. Manyar, D. Weber, H. Daly, J. M. Thompson, D. W. Rooney, L. F. Gladden, E. H. Stitt, J. J. Delgado, S. Bernal and C. Hardacre, J. Catal., 2009, 265, 80-88.

29 P. P. T. Krause, H. Camuka, T. Leichtweiss and H. Over, Nanoscale, 2016, 8, 13944-13953.

30 Ernst Ruska-Centre for Microscopy and Spectroscopy with Electrons (ER-C), A. Kovács, R. Schierholz and K. Tillmann, JLSRF, 2016, 2, A43.

31 Ernst Ruska-Centre for Microscopy and Spectroscopy with Electrons (ER-C), K. Tillmann, J. Barthel and L. Houben, JLSRF, 2015, 1, A34.

32 Ernst Ruska-Centre for Microscopy and Spectroscopy with Electrons (ER-C), M. Heggen, M. Luysberg and K. Tillmann, JLSRF, 2016, 2, A42.

33 E. H. Lock, D. Y. Petrovykh, P. Mack, T. Carney, R. G. White, S. G. Walton and R. F. Fernsler, Langmuir, 2010, 26, 8857-8868. 34 T. Weber, M. J. S. Abb, O. Khalid, J. Pfrommer, F. Carla, R. Znaiguia, V. Vonk, A. Stierle and H. Over, J. Phys. Chem. C, 2019, 123, 3979-3987.

35 D. N. Bunck and W. R. Dichtel, J. Am. Chem. Soc., 2013, 135, 14952-14955. 


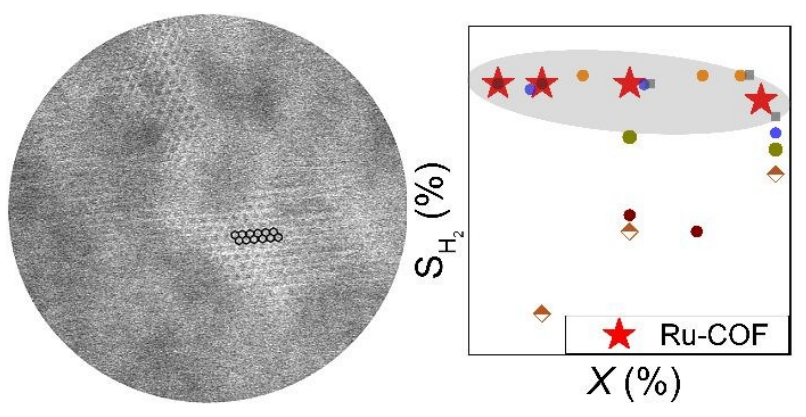

Selective formic acid dehydrogenation via efficient $\mathrm{RuO}_{2} / \mathrm{COF}$ pre-catalyst with good dispersion of active metal and large $\mathrm{N}$-content on the COF support. 